\title{
CLINICAL AND EPIDEMIOLOGICAL GENDERDIFFERENCESINPATIENTS WITH AXIAL SPONDYLOARTHRITIS IN A TERCIARY HOSPITAL
}

Fernanda Tavares de Melo Cavalcanti ${ }^{1, \star}$, Ana Carla Fernandes Oliveira', Thyago Talles de Almeida Santana', Sanna Paula Pires Mariano Campos ${ }^{1}$, Karla Valéria Miranda de Campos ${ }^{1}$, Alessandra de Sousa Braz ${ }^{1}$, Eutilia Andrade Medeiros Freire ${ }^{1}$, Maria Roberta Melo Pereira Soares ${ }^{1}$

1.Universidade Federal da Paraíba, João Pessoa (PB), Brazil.

*Corresponding author: fernandatavaresm@yahoo.com.br

\section{BACKGROUND}

Axial spondyloarthritis (SpA), especially ankylosing spondylitis (AS), has been known traditionally as a male disease. With the emergence of more sensitive complementary tests and new criteria for an early diagnosis, the prevalence in females has increased. Now, the ratio is three men for each woman. Given this fact, it is necessary to know the peculiarities of these diseases in women, especially for an effective treatment, in order to reduce sequels. The aim of this study was to evaluate clinical and epidemiological gender differences, in patients with SpA, recruited from a rheumatology outpatient clinic of a tertiary hospital in João Pessoa.

\section{MATERIALS AND METHODS}

Patients of both sexes, aged between 18 and 70 years old, that fulfilled the New York Modified criteria or the Assessment of Spondyloarthritis International Society (ASAS) group for SpA. Data were obtained from a clinical-demographic questionnaire showing information related to AS and nonradiographic axial spondyloarthritis (SpAnr), such as symptom and diagnosis duration, presence of radiographic and HLA-B27 changes, relationship with fibromyalgia, peripheral and extra-articular joint manifestations, evidence of inflammatory activity, disease, mobility and function activity indexes. Furthermore, variables related to the use of nonsteroidal anti-inflammatory, synthetic and biological disease modifying antirheumatic drugs were addressed.

\section{RESULTS}

The sample consisted of 47 patients, $66 \%$ male $(n=31)$ and $34 \%$ female $(n=16)$. The average age was $38.64 \pm 10.7$ years in women, while men were $44.7 \pm 10.4$ years old. Eighty-five percent of women and men were diagnosed with ankylosing spondylitis. Both had a long period of illness (16 years). In males, the time of diagnosis was $7 \pm 8.8$ years, while in females it was $3 \pm 4.5$ years, although men had a higher degree of sacroiliitis than women ( $p=0.037$ ). Both sexes had high disease activity (BASDAl $=3.52 \pm$ 3.12 in men and $4.0 \pm 2.68$ in women), with commitment of function (BASFI $=4.38 \pm 3.36$ men and $5.4 \pm 3.74$ women) and mobility (BASMI $=4.15 \pm 2.97$ men and $4.4 \pm 3.06$ women).

\section{CONCLUSIONS}

In this sample, women with SpA had less radiographic damage in sacroiliac than men. The other variables evaluated were not statistically significant. More studies are needed, with a larger sample size, to better understand the differences between sexes. Keywords: axial spondyloarthritis, ankylosing spondylitis, gender differences. 